\title{
DIVERGÊNCIA GENÉTICA EM LINHAGENS DE PIMENTÃO EM RELAÇÃO À EFICIÊNCIA NUTRICIONAL DE FÓSFORO'1
}

\author{
WALDÊNIA DE MELO MOURA², VICENTE WAGNER DIAS CASALI ${ }^{3}$, \\ COSME DAMIÃO CRUZ ${ }^{4}$ e PAULO CÉSAR DE LIMA ${ }^{5}$
}

\begin{abstract}
RESUMO - Avaliaram-se 10 linhagens de pimentão (Capsicum annuum L.) quanto à eficiência nutricional em relação ao $\mathrm{P}$, bem como a dose de $\mathrm{P}$ mais adequada para estudos genéticos, e o caráter que mais contribuiu para a divergência genética. $O$ experimento foi conduzido em casa de vegetação, em solo, na Universidade Federal de Viçosa. Os tratamentos foram distribuídos em arranjo fatorial $10 \times 5 \times 4$, constituídos de 10 linhagens, cinco doses de P (0, 250, 500, 750 e $1.000 \mathrm{mg}$ de $\mathrm{P} / \mathrm{kg}$ de solo) e quatro repetições, em delineamento de blocos casualizados. Em cada dose de P aplicada ao solo foi realizada uma análise multivariada. Constatou-se variabilidade genética entre as linhagens estudadas em todas as doses de $\mathrm{P}$ adicionadas ao solo, sendo a dose $250 \mathrm{mg}$ de $\mathrm{P} / \mathrm{kg}$ de solo a que melhor discriminou as linhagens; portanto, a mais indicada para estudos genéticos. Com essa dosagem, constatou-se que a produção de matéria seca da parte aérea foi o caráter que mais contribuiu para a divergência genética entre as linhagens, podendo ser um parâmetro adequado para seleção em estudos genéticos.
\end{abstract}

Termos para indexação: Capsicum annuum, variabilidade genética, análise multivariada, doses de P.

\section{GENETIC DIVERGENCE OF PHOSPHORUS NUTRITIONAL EFFICIENCY IN SWEET PEPPER LINES}

\begin{abstract}
Ten sweet pepper (Capsicum annuum L.) lines were screened for P nutritional efficiency, as well as for the most adequate $\mathrm{P}$ dose for genetic studies and the character that most contributed for genetic divergence. An experiment was conducted in soil sack, in a greenhouse at Universidade Federal de Viçosa, UFV, Brazil. The treatments were arranged in a factorial layout $(10 \times 5) \times 4$, comprising ten lines, five doses of $\mathrm{P}(0,250,500,750$ and $1,000 \mathrm{mg} \mathrm{P} / \mathrm{kg}$ of soil $)$ and four replicates, in a randomized block design. A multivariate analysis was performed for each dose of $\mathrm{P}$ applied in the soil. There was genetic divergence among lines in every dose of P studied. The dose $250 \mathrm{mg} \mathrm{P} / \mathrm{kg}$ of soil was considered as the best to rank the lines, therefore, it is indicated for genetic studies. With this dose, shoot dry matter was the trait that contributed most for genetic divergence among lines, and it should be an adequate parameter for screening for $\mathrm{P}$ efficiency in genetic studies.
\end{abstract}

Index terms: Capsicum annuum, genetic variability, multivariate analysis, $\mathrm{P}$ doses.

\section{INTRODUÇÃO}

A importância da diversidade genética para o melhoramento reside no fato de que cruzamentos envolvendo progenitores geneticamente diferentes são os mais convenientes para produzir alto efeito

\footnotetext{
${ }^{1}$ Aceito para publicação em 27 de julho de 1998. Trabalho realizado com apoio financeiro da FAPEMIG.

${ }^{2}$ Eng $^{\text {a }}$ Agr $^{\mathrm{a}}$, Dr ${ }^{\mathrm{a}}$, EPAMIG, Caixa Postal 216, CEP 36571-000 Viçosa, MG. E-mail: waldenia@mail.ufv.br

${ }^{3}$ Eng. Agr., Ph.D, Prof. Titular, Dep. de Fitotecnia, Univ. Fed. de Viçosa (UFV), CEP 36571-000 Viçosa, MG.

${ }^{4}$ Eng. Agr., Dr., Prof. Titular, Dep. de Biologia Geral, UFV.

${ }^{5}$ Eng. Agr., Dr., EPAMIG.
}

heterótico e, também, maior variabilidade genética em gerações segregantes (Rao et al., 1981). Tem-se constatado ampla diversidade em várias espécies de plantas quanto à eficiência nutricional em relação ao P (Whiteaker et al., 1976; Coltman et al., 1985; Furlani, et al., 1985; Föhse et al., 1988). Essa diversidade constitui a base genética para programas de melhoramento e é decorrente de uma série de mecanismos fisiológicos, morfológicos e bioquímicos desenvolvidos pelas plantas quando submetidas às condições adversas de fertilidade do solo, principalmente sob estresse de P. Entretanto, alguns aspectos têm limitado avanços nessa área de pesquisa, como a falta de técnicas de cultivo para a avaliação da variabilidade genética disponíveis no germoplasma, pois a 
maioria das técnicas utilizadas não são efetivas na identificação de mecanismos desenvolvidos pelas plantas em condições naturais de campo. Outro ponto a considerar é a identificação de um caráter de fácil avaliação para que possa ser utilizado como parâmetro de seleção. Também, o conhecimento da dose de $\mathrm{P}$ adequada a ser utilizada nesses trabalhos tem sido questionado. Na busca de soluções para tais pontos críticos, várias sugestões têm sido relatadas. Furlani et al. (1985) sugeriram a realização de estudos preliminares utilizando uma amostra dos genótipos, cultivada em doses crescentes de P para o conhecimento prévio dos caracteres e da dose adequada desse elemento que melhor discriminem os genótipos, ou seja, que detectem maior variabilidade genética, para posterior avaliação de um grande número de genótipos. Entretanto, tal proposta requer tempo, espaço e mão-de-obra. Por sua vez, as análises estatísticas dos resultados obtidos de cada caráter avaliado são feitas individualmente, o que dificulta uma interpretação mais global. Nesse contexto, vários parâmetros têm sido utilizados na tentativa de melhor caracterizar a eficiência em relação ao P. Assim, no trevo branco (Trifolium repens L.) o controle genético da eficiência foi associado com o número de pêlos radiculares (Caradus, 1982) e em tomate, com o comprimento de pêlos radiculares, demonstrando ser um caráter monogênico e recessivo (Hochmuth et al., 1985). Já no feijão, a eficiência em relação ao $P$ associou-se com os seguintes caracteres: produção de matéria seca/unidade de $\mathrm{P}$ absorvido (Whiteaker et al., 1976), produção de matéria seca total (Fawole et al., 1982b) e a produção de matéria seca de raiz (Fawole et al., 1982a); o primeiro caráter apresentou herança bastante complexa, enquanto os demais herança quantitativa e alta herdabilidade.

A determinação da divergência genética, com o uso da análise multivariada, em que diversos caracteres avaliados podem ser dimensionados simultaneamente nos genótipos, apresenta-se bastante vantajosa, podendo-se identificar fontes de variabilidade genética, a importância de cada caráter avaliado em relação à divergência genética e a dose de $\mathrm{P}$ mais adequada para estudos genéticos, além de permitir aos melhoristas conhecer as combinações com maiores chances de sucesso, antes de se realizarem os cruzamentos. A técnica de análise multivariada foi bastante promissora na discriminação de genótipos de alface em resposta às adubações orgânica e mineral de N (Rodrigues, 1995), na tolerância de genótipos de arroz à toxidez de $\mathrm{Al}$ (Ferreira, 1995) e na tolerância ao baixo teor de $\mathrm{P}$ no solo do pimentão (Oliveira, 1997).

Este trabalho teve como objetivo verificar a viabilidade da análise multivariada na identificação de fontes de variabilidade genética entre linhagens de pimentão quanto à eficiência nutricional para o $\mathrm{P}$, bem como determinar a dose mais adequada desse elemento para estudos genéticos futuros e a característica da planta mais apropriada para o processo de seleção.

\section{MATERIAL E MÉTODOS}

$\mathrm{O}$ experimento foi realizado em casa de vegetação do Departamento de Fitotecnia da Universidade Federal de Viçosa, em Viçosa, MG. O material vegetal utilizado originou-se do cruzamento entre dois híbridos: (BGH $4562 \mathrm{x}$ BGH 4561) e (BGH 18 x BGH 2665). O híbrido duplo obtido foi posteriormente cruzado com um terceiro híbrido (BGH 18 x BGH 2854), obtendo-se 200 linhagens, as quais foram avançadas até as gerações $F_{12}$, sem seleção artificial. Em função da quantidade de sementes disponível, selecionaram-se 10 linhagens para este estudo. Utilizou-se um solo com baixo teor de $\mathrm{P}$, classificado como LU (Latossolo variação UNA), do município de Viçosa. A amostra do solo foi coletada na camada subsuperficial $(0-20 \mathrm{~cm})$, seca ao ar, destorroada, passada em peneiras com abertura de $4 \mathrm{~mm}$ e homogeneizada. Subamostras foram utilizadas para caracterizações química e física, apresentando $\mathrm{pH}$ 5,1 e 1,5 mg de P/ $\mathrm{dm}^{3}$ (Vettori, 1969), e solo classificado como muito argiloso. A acidez do solo foi corrigida, fazendo-se a calagem de acordo com as recomendações da Comissão de Fertilidade do Solo do Estado de Minas Gerais (1989) e a aplicação de calcário com dose equivalente a 3,19 t/ha, com relação Ca:Mg de 4:1, em equivalente. Posteriormente, adicionou-se $1 \mathrm{meq} / 100 \mathrm{~cm}^{3}$ de $\mathrm{Mg}\left(\mathrm{MgCl}_{2} \cdot 6 \mathrm{H}_{2} \mathrm{O}\right)$, em coberturas parceladas em cinco aplicações semanais, reduzindo a relação Ca:Mg para 2:1, em equivalente. Após a calagem, adicionou-se o $P$ nas doses de $0,250,500,750$ e $1.000 \mathrm{mg}$ de $\mathrm{P} / \mathrm{kg}$ de solo, fornecidas numa combinação dos seguintes sais P.A.: $\left(\mathrm{NH}_{4}\right) \mathrm{H}_{2} \mathrm{PO}_{4}, \mathrm{KH}_{2} \mathrm{PO}_{4}, \mathrm{NaH}_{2} \mathrm{PO}_{4}$ e $\mathrm{Ca}\left(\mathrm{H}_{2} \mathrm{PO}_{4}\right) \cdot \mathrm{H}_{2} \mathrm{O}$. Os demais macro e micronutrientes foram fornecidos nas seguintes doses, em $\mathrm{mg}$ do elemento/kg de solo: $\mathrm{N}-300$; K-150; S-50; Zn- 4; Cu-1,33; Fe-1,56; Mo-0,15; B-0, 18 e Mn-3,66. A aplicação de $\mathrm{N}$ em cobertura iniciou-se aos 
15 dias após o plantio, sendo feitas cinco coberturas em intervalos semanais. Os micronutrientes foram aplicados aos 13, 20 e 29 dias após o plantio. Após a adubação básica, o solo foi acondicionado em vasos de plástico com capacidade para $5 \mathrm{~kg}$ de solo e irrigado com água desmineralizada, mantendo-se a umidade em torno de $80 \%$ da capacidade de campo (C.C.). Posteriormente, esses vasos foram submetidos a um período de incubação de 30 dias, à temperatura ambiente, em casa de vegetação. Em seguida, efetuou-se o plantio, utilizando quatro sementes por vaso. Quando as plântulas apresentaram duas folhas definitivas realizou-se o desbaste, deixando uma planta por vaso. Durante a condução do experimento, o solo foi mantido com a umidade próxima da C.C., realizando-se as capinas manuais e o tutoramento das plantas. O experimento foi conduzido por 120 dias, quando, então, foi colhido. Durante todo o período experimental foram feitas colheitas de frutos à medida que se apresentavam maduros. Avaliaram-se as seguintes características: altura da planta; peso médio de fruto; peso da matéria seca de raiz, caule, folha e fruto; relação raiz/parte aérea. Após secagem, a matéria seca foi moída em moinho Willey, com peneira $\mathrm{n}^{\circ} 20$, homogeneizada e retiradas amostras de $2 \mathrm{~g}$, as quais foram submetidas à digestão nitroperclórica; no extrato obtido foram determinados os teores de P (Braga \& Defelipo, 1974). Uma vez obtidos os dados de matéria seca e os conteúdos de $\mathrm{P}$, estimaram-se os seguintes índices de eficiência, baseado no conceito proposto por Siddiqi \& Glass (1981), que reuniram num mesmo índice a eficiência para $\mathrm{P}$ e o crescimento da planta: Eficiência de translocação de $\mathrm{P}$ (ETP): $\mathrm{mg}$ de $\mathrm{P}$ na parte aérea/mg de $\mathrm{P}$ total; Eficiência de utilização do P na parte aérea (EUPPA): $\mathrm{g}^{2}$ de matéria seca da parte aérea/mg de $\mathrm{P}$ na parte aérea; Eficiência de utilização do $\mathrm{P}$ total (EUPT): $\mathrm{g}^{2}$ de matéria seca total/mg de P total; Eficiência de utilização do P foliar para a produção de matéria seca da parte aérea (EUPAFO): $\mathrm{g}^{2}$ de matéria seca de parte aérea/mg de $\mathrm{P}$ na folha; Eficiência de utilização do $\mathrm{P}$ foliar para a produção de matéria seca total (EUTFO): $\mathrm{g}^{2}$ de matéria seca total $/ \mathrm{mg}$ de $\mathrm{P}$ na folha, e Eficiência de utilização do $P$ da parte aérea para a produção de matéria seca de fruto (EUFRPA): $\mathrm{g}^{2}$ de matéria seca de fruto/mg de $\mathrm{P}$ na parte aérea.

Os dados obtidos de cada variável foram submetidos à análise de variância e posteriormente foram feitas análises multivariadas para cada dose de $\mathrm{P}$ aplicada no solo. Para a discriminação genotípica entre as linhagens, utilizou-se a análise de agrupamento, pelo método de Tocher citado por Rao (1952), baseada na distância generalizada de Mahalanobis, cujo princípio básico é manter a homogeneidade dentro e heterogeneidade entre os grupos formados. Por meio desta técnica, o nível de P mais ade- quado para estudos genéticos futuros é aquele que proporciona melhor discriminação entre as linhagens, ou seja, que apresenta maior número de grupos distintos de linhagens. A contribuição relativa de cada característica avaliada para a diversidade entre as linhagens foi obtida pela metodologia proposta por Singh (1981).

\section{RESULTADOS E DISCUSSÃO}

Considerando as médias dos 15 caracteres avaliados (Tabela 1), por meio da análise multivariada constataram-se variabilidade genética entre as linhagens em todas as doses de $\mathrm{P}$ adicionadas ao solo (Tabela 2). De modo geral, as linhagens L8 e L10 permaneceram individualmente em grupos distintos independentemente da dose de P considerada, significando que elas apresentam-se bastante divergentes em relação às demais linhagens. Observa-se também que as linhagens L1, L5 e L9 mantiveram-se no mesmo grupo independentemente da dose de $\mathrm{P}$, significando que essas linhagens são muito próximas geneticamente. As demais linhagens comportaramse de modo variado de acordo com a dose de $\mathrm{P}$, sugerindo que são mais flexíveis em relação à adubação fosfatada.

Entre as doses de $\mathrm{P}$ adicionadas ao solo, na $250 \mathrm{mg}$ de $\mathrm{P} / \mathrm{kg}$ de solo observou-se maior variabilidade genética entre as linhagens, pois apresentou cinco grupos distintos, enquanto as demais doses apresentaram quatro (Tabela 2). Assim, essa dose pode ser considerada como a mais indicada para estudos de avaliação de genótipos de pimentão em estudos genéticos futuros. A dose $250 \mathrm{mg}$ de $\mathrm{P} / \mathrm{kg}$ de solo foi um valor intermediário entre aquelas recomendadas para os níveis críticos de $\mathrm{P}$ obtidos para essas dez linhagens (454 mg de P/kg de solo em média) (Moura, 1996), e as doses obtidas em relação à tolerância ao baixo teor de $\mathrm{P}$ no solo ( $84 \mathrm{mg}$ de $\mathrm{P} / \mathrm{kg}$ de solo em média e $200 \mathrm{mg}$ de $\mathrm{P} / \mathrm{kg}$ de solo) encontradas por Moura (1996) e Oliveira (1997), respectivamente.

Uma vez constatado que a dose de $250 \mathrm{mg}$ de $\mathrm{P} / \mathrm{kg}$ de solo apresentou a maior divergência, o próximo passo foi determinar o caráter que mais contribuiu para essa divergência. Entre os 15 caracteres avaliados, a produção de matéria seca da parte aérea apresentou a maior percentagem de contribuição 


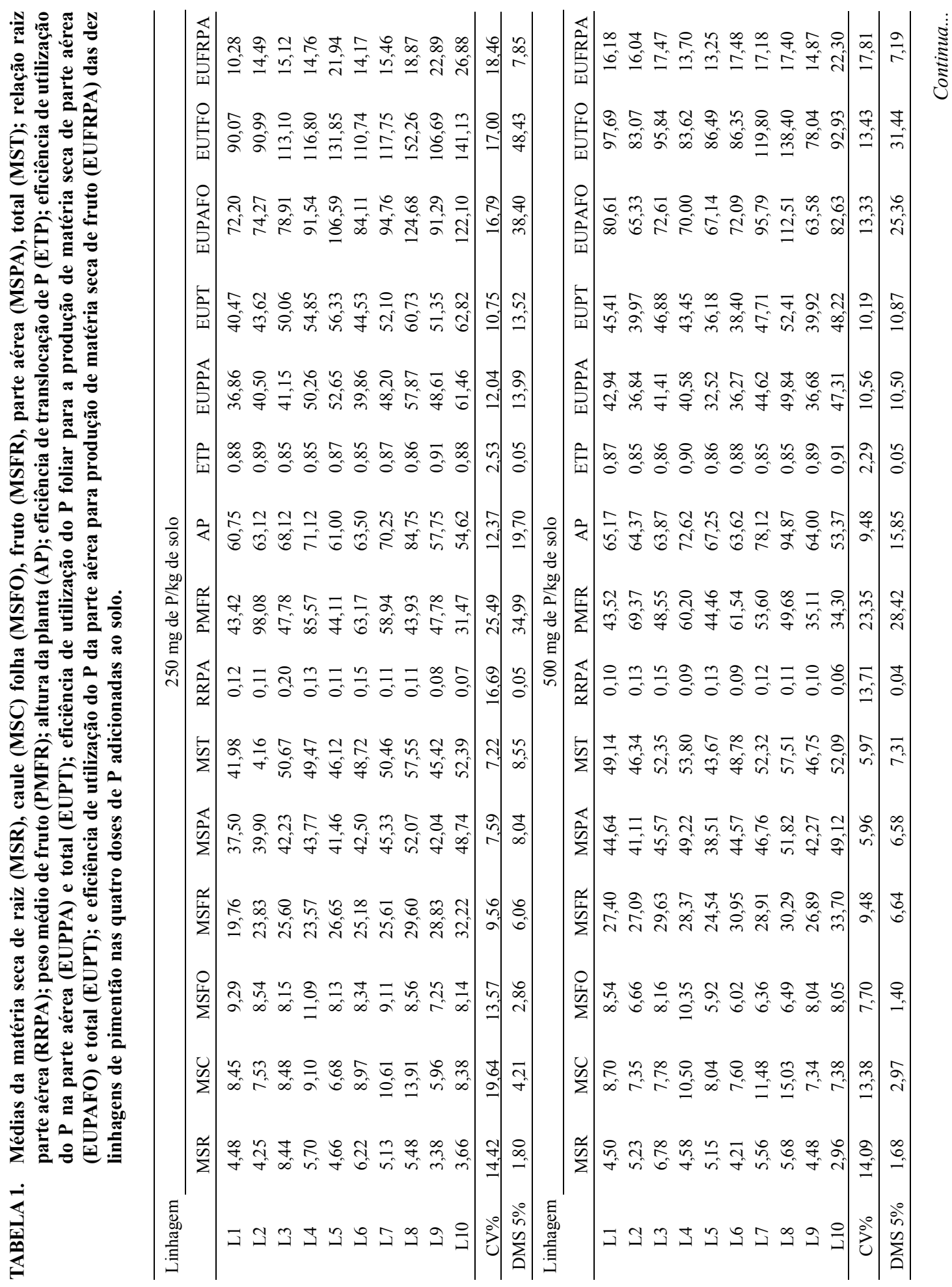




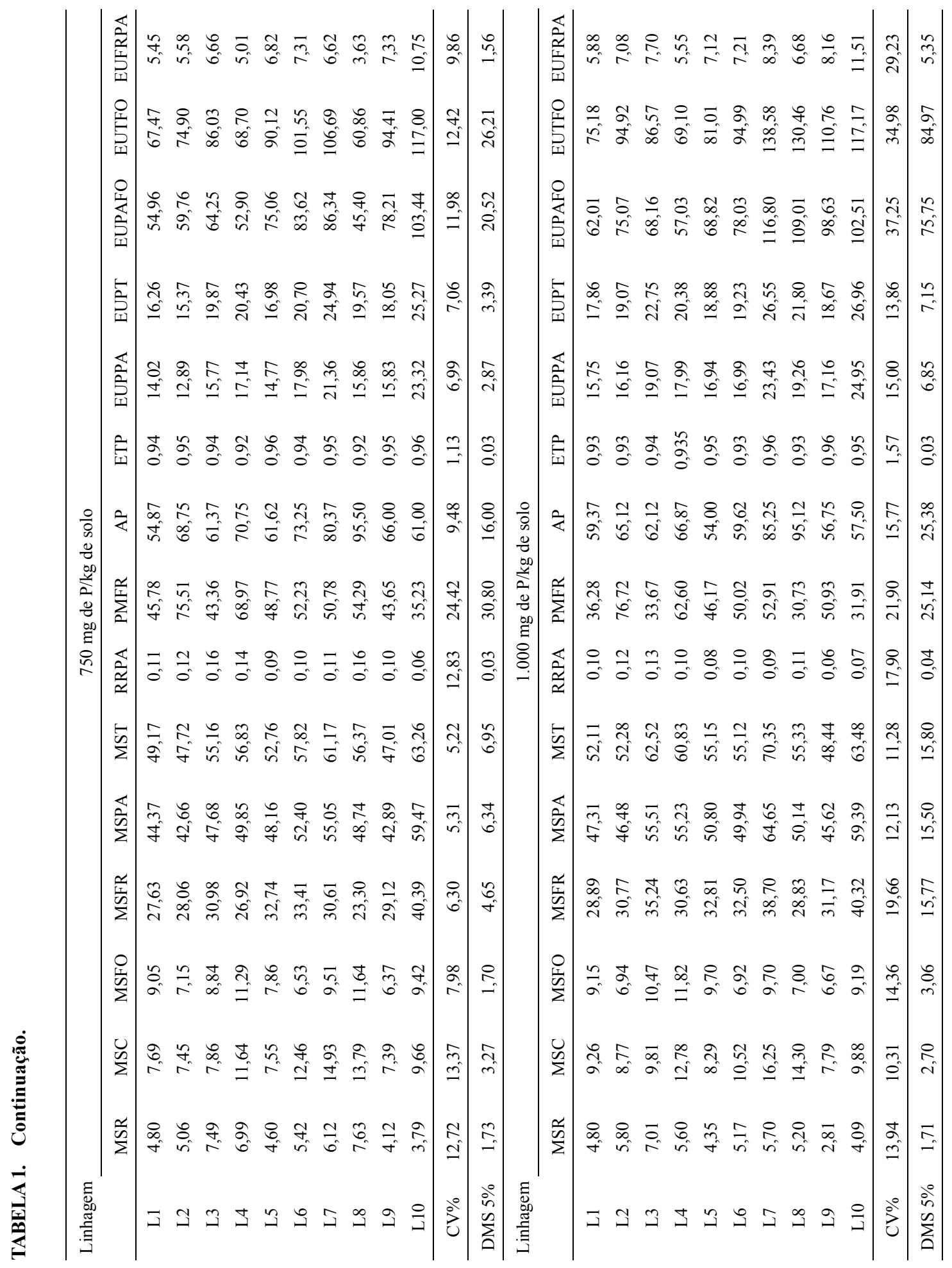


quanto à divergência genética $(23,6 \%)$ (Tabela 3), podendo ser utilizada como parâmetro de seleção na avaliação de genótipos eficientes em relação ao P. Assim, as linhagens L8 e L10 foram as mais eficien- tes para P, já as linhagens L1 e L2 foram as menos eficientes e as demais linhagens podem ser consideradas de intermediária eficiência (Tabela 1). A matéria seca de parte aérea foi o caráter utilizado por Silva

TABELA 2. Agrupamento das dez linhagens de Pimentão (L) pelo método de Tocher, considerando as seguintes características: matéria seca de raiz, caule, folha, fruto, parte aérea, total, relação raiz/parte aérea, peso médio de fruto, altura da planta, eficiência de translocação do $P$, eficiência de utilização do $P$ na parte aérea, eficiência de utilização do $P$ total, eficiência de utilização do $P$ foliar para produção de matéria seca da parte aérea e para produção de matéria seca total, e eficiência de utilização do $P$ da parte aérea para produção de matéria seca de fruto, nas quatro doses de $P$ adicionas ao solo.

\begin{tabular}{cllll}
\hline \multirow{2}{*}{ Grupo } & \multicolumn{4}{c}{ Doses de P (mg/kg de solo) } \\
\cline { 2 - 5 } & \multicolumn{1}{c}{250} & \multicolumn{1}{c}{500} & \multicolumn{1}{c}{ 750 } \\
\hline 1 & L5, L9, L7, L1 & L5, L6, L2, L9, L3, L7, L1 & L2, L5, L1, L6, L9, L7, L4 & L1, L5, L9, L3 \\
2 & L2, L4 & L10 & L3 & L2, L6, L4 \\
3 & L3, L6 & L8 & L8 & L7, L8 \\
4 & L8 & L4 & L10 & L10 \\
5 & L10 & & & \\
\hline
\end{tabular}

TABELA3. Contribuição relativa no tocante à divergência genética (S.j) e em \% dos seguintes caracteres: matéria seca de raiz (MSR), caule (MSC), folha (MSFO), fruto (MSFR), parte aérea (MSPA), total (MST), relação raiz/parte aérea (R/PA), peso médio de fruto (PMFR), altura da planta (AP), eficiência de translocação do P (ETP), eficiência de utilização do P na parte aérea (EUPPA) e total (EUPT), eficiência de utilização do $P$ foliar para produção de matéria seca da parte aérea (EUPAFO) e matéria seca total (EUTFO), eficiência de utilização do $P$ da parte aérea para produção de matéria seca de fruto (EUFRPA), nas quatro doses de $P$ adicionadas ao solo.

\begin{tabular}{|c|c|c|c|c|c|c|c|c|}
\hline \multirow[t]{3}{*}{ Caracteres } & \multicolumn{8}{|c|}{ Doses de P ( $\mathrm{mg} / \mathrm{kg}$ de solo $)$} \\
\hline & \multicolumn{2}{|c|}{250} & \multicolumn{2}{|c|}{500} & \multicolumn{2}{|c|}{750} & \multicolumn{2}{|c|}{1.000} \\
\hline & S.j & $\%$ & S.j & $\%$ & S.j & $\%$ & S.j & $\%$ \\
\hline MSR & 474,3 & 7,3 & 627,7 & 6,2 & $5.734,1$ & 16,0 & 158,5 & 0,5 \\
\hline MSC & 424,2 & 6,5 & 573,9 & 5,7 & 994,5 & 2,8 & $6.356,1$ & 18,8 \\
\hline MSFO & 255,7 & 3,9 & $2.527,9$ & 25,0 & 388,0 & 1,1 & 354,0 & 1,0 \\
\hline MSFR & 481,9 & 7,4 & 988,1 & 9,8 & 592,9 & 1,6 & $2.131,8$ & 6,3 \\
\hline MSPA & $1.534,5$ & 23,6 & $1.182,6$ & 11,7 & 600,8 & 1,7 & $5.103,3$ & 15,1 \\
\hline MST & 95,3 & 1,5 & 248,6 & 2,4 & $1.357,3$ & 3,8 & $8.772,1$ & 25,9 \\
\hline $\mathrm{R} / \mathrm{PA}$ & 99,8 & 1,5 & 431,0 & 4,3 & $3.082,4$ & 8,6 & 276,2 & 0,8 \\
\hline PMFR & 314,1 & 4,8 & 88,1 & 0,9 & 285,4 & 0,8 & 978,9 & 2,9 \\
\hline $\mathrm{AP}$ & 13,51 & 0,2 & 58,8 & 0,6 & 146,0 & 0,4 & 134,2 & 0,4 \\
\hline ETP & 12,1 & 0,2 & 555,4 & 5,5 & 24,0 & 0,1 & 264,5 & 0,8 \\
\hline EUPPA & 477,0 & 7,3 & 119,4 & 1,2 & $5.789,3$ & 16,1 & 299,4 & 0,9 \\
\hline EUPT & 231,7 & 3,6 & 468,4 & 4,6 & $2.921,3$ & 8,1 & 337,2 & 1,0 \\
\hline EUPAFO & $1.232,8$ & 18,9 & 327,4 & 3,2 & $7.714,2$ & 21,5 & $3.793,5$ & 11,2 \\
\hline EUTFO & 525,99 & 8,1 & 826,8 & 8,2 & $6.149,8$ & 17,1 & $3.686,5$ & 10,9 \\
\hline EUFRPA & 329,40 & 5,1 & $1.090,5$ & 10,8 & 131,7 & 0,4 & $1.209,0$ & 3,6 \\
\hline
\end{tabular}


\& Gabelman (1992), na discriminação de genótipos de milho tolerantes ao estresse causado pela deficiência de P. Entretanto, nessas mesmas condições nutricionais, a produção de matéria seca total também tem sido um parâmetro recomendado na avaliação da eficiência para P em feijão (Fawole et al., 1982b); tomate (Coltman et al., 1985); milho (Furlani et al., 1985); e pimentão (Oliveira, 1997), pois obteve-se mais contribuições da matéria seca de raiz na matéria seca total nessa condição nutricional.

Vários autores têm observado que o aumento da disponibilidade de $\mathrm{P}$ no solo reduz a relação raiz/parte aérea, em virtude de maiores aumentos na produção de matéria seca da parte aérea do que da raiz (Fawole et al., 1982b; Furlani \& Usberti Filho, 1990; Martinez et al., 1993), porém tal comportamento não deve ser generalizado para todas as espécies de plantas. Segundo Clarkson (1985), quando alguns nutrientes limitam o crescimento das plantas, principalmente $\mathrm{P}$ e N , as raízes tornam-se drenos relativamente mais fortes para carboidratos em relação à parte aérea, ocorrendo com isso redução desta antes que as raízes sejam afetadas. Também a redução do crescimento da parte aérea em condições de deficiência de $\mathrm{P}$ pode estar relacionada com o decréscimo da produção de citocinina nas raízes e a redução da translocação desta para a parte aérea (Sattelmacher $\&$ Marshner, 1978). A citocinina está envolvida na senescência das folhas, e de forma indireta no fechamento dos estômatos.

Observa-se ainda que na dose $250 \mathrm{mg}$ de $\mathrm{P} / \mathrm{kg}$ de solo (Tabela 2) os caracteres eficiência de translocação do P, altura de planta, matéria seca total, relação raiz/parte aérea, eficiência de utilização do P total, matéria seca de folha, peso médio de fruto e eficiência de utilização do $\mathrm{P}$ da parte aérea para a produção de matéria seca da parte aérea foram em ordem decrescente as características que apresentaram as menores contribuições para a divergência genética, sendo, portanto, dispensável a sua avaliação em estudos futuros. Segundo Cruz \& Regazzi (1994), caracteres dispensáveis em estudos de divergência genética são aqueles invariantes entre os genótipos estudados ou reduntantes, por estarem correlacionados com outros caracteres. Em condições de baixo teor de P no solo, Oliveira (1997) também verificou que em relação ao pimentão a eficiên- cia de translocação de $\mathrm{P}$ e a relação raiz parte aérea foram caracteres invariantes.

Embora a matéria seca da parte aérea neste trabalho tenha sido o caráter de maior importância na dose $250 \mathrm{mg}$ de $\mathrm{P} / \mathrm{kg}$ de solo, a sua contribuição para a divergência genética entre as linhagens não permaneceu constante à medida que se aumentou a dose de P no solo, mas os outros caracteres que apresentaram maiores contribuições quanto à divergência genética em doses mais elevadas de $\mathrm{P}$ tiveram a matéria seca da parte aérea como seu principal componente (Tabela 3). Contudo, evidencia-se que o caráter a ser utilizado como parâmetro de seleção visando ao aumento da eficiência em relação ao $\mathrm{P}$ pode variar com a dose de $\mathrm{P}$ aplicada ao solo.

\section{CONCLUSÕES}

1. A análise multivariada é efetiva para detectar divergência genética quanto à eficiência nutricional no tocante ao $\mathrm{P}$ e à dose de $\mathrm{P}$ mais apropriada para estudos genéticos, como também para identificar o caráter que mais contribui para essa divergência.

2. A dose $250 \mathrm{mg} \mathrm{P} / \mathrm{kg}$ de solo e a produção de matéria seca da parte aérea são as mais indicadas para estudos de divergência genética em pimentão visando ao aumento da eficiência em relação ao $\mathrm{P}$.

\section{REFERÊNCIAS}

BRAGA, J.M.; DEFELIPO, B.V. Determinações espectrofotométricas de fósforo em extratos de solos e material vegetal. Revista Ceres. Viçosa, v.21, n.113, p.73-85, jan./fev. 1974.

CARADUS, J.R. Genetic differences in the length of root hairs in white clover and their effect on phosphorus uptake. In: SCAIFER, A. (Ed.). Plant Nutrition. Slough: Commonwealth Agricultural Bureau, 1982. v.1, p.84-88.

CLARKSON, D.T. Factors affecting mineral nutrient acquisition by plants. Annual Review of Plant Physiology. Palo Alto, v.36, p.77-115, 1985.

COLTMAN, R.R.; GERLOFF, G.C.; GABELMAN, W.H. Differential tolerance of tomato strains to main-

Pesq. agropec. bras., Brasília, v.34, n.2, p.217-224, fev. 1999 
tained and deficient levels of phosphorus. Journal of the American Society for Horticultural Science, v.110, n.2, p.140-144, Mar. 1985.

COMISSÃO DE FERTILIDADE DO SOLO DO ESTADO DE MINAS GERAIS. Recomendações para o uso de corretivos e fertilizantes em Minas Gerais: 4a. Aproximação. Lavras: CFSEMG, 1989. $176 \mathrm{p}$.

CRUZ, C.D.; REGAZZI, A.J. Modelos biométricos aplicados ao melhoramento genético. Viçosa: UFV, 1994. 390p.

FAWOLE, I.; GABELMAN, W.H.; GERLOFF, G.C. Genetic control of root development in beans (Phaseolus vulgaris L.) grown under phosphorus stress. Journal of the American Society for Horticultural Science, v.107, n.1, p.98-100, Jan. 1982a.

FAWOLE, I.; GABELMAN, W.H.; GERLOFF, G.C.; NORDHEIM, E.V. Heritability of efficiency in phosphorus utilization in beans (Phaseolus vulgaris L.) grown under phosphorus stress. Journal of the American Society for Horticultural Science, v.107, n.1, p.94-97, Jan. 1982b.

FERREIRA, R.P. Análises biométricas da tolerância do arroz (Oryza sativa $\mathrm{L}$.) à toxidez de alumínio. Viçosa: UFV, 1995. 123p. Tese de Doutorado

FÖHSE, D.; CLAASSEN, N.; JUNGK, A. Phophorus efficiency of plants. I. External and internal $\mathrm{P}$ requeriment and $\mathrm{P}$ uptake efficiency of different plant species. Plant and Soil, New York, v.110, n.1, p.101-109, Aug. 1988.

FURLANI, A.M.C.; BATAGLIA, O.C.; LIMA, M. Eficiência de linhagens de milho na absorção e utilização de fósforo em solução nutritiva. Bragantia, Campinas, v.44, Tomo 1, p.129-147, 1985.

FURLANI, A.M.C.; USBERTI FILHO, J.A. Capimcolonião: eficiência na absorção e na utilização de fósforo em solução nutritiva. Bragantia, Campinas, v.49, n.2, p.413-423, 1990.

HOCHMUTH, G.J.; GABELMAN, W.H.; GERLOFF, G.C. A gene affecting tomato root morphology. HortScience, v.20, n.6, p.1099-1101, 1985.

MARTINEZ, H.E.P.; NOVAIS, R.F.; RODRIGUES, L.A.; SACRAMENTO, L.V.S. Comportamento de variedades de soja cultivadas em diferentes doses de fósforo: I. Cinética de absorção de fósforo e ajustes morfológicos da planta. Revista Brasileira de Ciências do Solo, Campinas, v.17, p.231-238, 1993.

MOURA, W.M. Eficiência nutricional para fósforo em linhagens de pimentão (Capsicum annuum L.). Viçosa: UFV, 1996. 102p. Tese de Doutorado.

OLIVEIRA, V.R. Diversidade genética em pimentão (Capsicum annuum L.) e controle gênico da tolerância ao baixo teor de fósforo no solo. Viçosa: UFV, 1997. 102p. Tese de Doutorado.

RAO, R.C. Advanced statistical methods in biometric research. New York: John Wiley and Sons, 1952. 390 p.

RAO, A.V.; PRASAD, A.S.R.; SAI KRISHNA, T.; SECHU, D.V.; SRINIVASAN, T.E. Genetic divergence among some brown planthopper resistant rice varieties. The Indian Journal of Genetic Plant Breeding, New York, v.41, n.2, p.179-185, July 1981.

RODRIGUES, E.T. Seleção de cultivares de alface (Lactuca sativa $\mathrm{L}$.) para cultivo com composto orgânico. Viçosa: UFV, 1995. 164p. Tese de Doutorado.

SATTELMACHER, B.; MARSHNER, H. Nitrogen nutrition and cytokinin activity in Solanum tuberosum. Physiologia Plantarum, Copenhagem, v.42, p.185-189, 1978.

SIDDIQI, M.Y.; GLASS, A.D.M. Utilization index: a modified approach to the estimation and comparision of nutrient utilization efficiency in plants. Journal of Plant Nutrition, New York, v.4, n.3, p.289-302, 1981.

SILVA, A.E.; GABELMAN, W.H. Screening maize inbred lines for tolerance to low-P stress condition. Plant and Soil, New York, v.146, n.1/2, p.181-197, 1992.

SINGH, D. The relative importance of characters affecting genetic divergence. The Indian Journal of Genetics and Plant Breeding, New York, v.41, n.2, p.237245, July 1981.

VETTORI, L. Métodos de análise de solo. Rio de Janeiro: EPFS-EPE, 1969. 24p. (Boletim técnico, 7).

WHITEAKER, G.; GERLOFF, G.C.; GABELMAN, W.H. Intraspecific differences in growth of beans at stress levels of phosphorus. Journal of the American Society for Horticultural Science, v.101, n.4, p.472-475, July 1976. 